\title{
Limit height-to-width aspect ratios for slender base isolated objects of heritage architecture
}

\author{
S. Petrovčič, D. Koren \& V. Kilar \\ Faculty of Architecture, University of Ljubljana, Slovenia
}

\begin{abstract}
Seismic isolation has become a realistic alternative for decreasing the seismic vulnerability of heritage architecture. This article deals with a special technical aspect of base isolation design of slender rigid objects on elastomeric isolators, by considering the condition that the isolators cannot bear any tensile forces under simultaneous horizontal and vertical ground excitations. The main parameters that govern the response in this case are a) mass, mass position and height-to-width aspect ratios of the superstructure, b) stiffness, damping and plan arrangement of the isolators and c) expected horizontal as well as vertical earthquake acceleration components and their interconnections. The limit height-to-width aspect ratios were obtained for horizontal and vertical accelerations from the Eurocode 8 response spectra, as well as from dynamic analyses of seven near-fault ground motion records. The results are presented as maximum allowable aspect ratios for different vibration periods, ground conditions and design ground accelerations. The inclusion of vertical accelerations in governing equations is extremely important because different horizontal and vertical seismic loading combinations might significantly influence the maximum allowable height-to-width aspect ratios. The article concludes that the results from the response spectrum analysis are conservative. Although, in some ground motion records, the critical combination of horizontal and vertical response accelerations can also produce smaller limit height-towidth aspect ratios.

Keywords: base isolation, elastomeric isolators, limit aspect ratios, vertical and horizontal ground excitations.
\end{abstract}




\section{Introduction}

Increasing seismic safety of existing structures demands a relatively extensive intervention into the structure itself, thus such remedial action on existing residential and office buildings is rarely taken. The situation is different with buildings of special significance, which have, for example, high financial or cultural value. The latter group includes mainly cultural heritage objects, where also using more expensive technological solutions for protection against earthquakes is no object. In the context of this article, the term "cultural heritage" comprises places of heritage architecture, namely buildings and monuments, which, in addition to their practical and functional value, also display special cultural and historical characteristics.

Increased seismic safety can be achieved by inserting special elastomeric isolators, which are usually installed at the foundation level of a structure. The elastomeric isolators extend the structure's vibration period and reduce the forces to the structure induced by an earthquake. Restoration of heritage architecture is, due to the high cultural value, usually extremely demanding. According to the Burra Charter [1], cultural heritage places need to be protected and should not be exposed to dangers or be left unprotected. Interventions into such structures should be minimal or visible as little as possible and should minimally affect the aesthetics and functionality of the monument. Frequently with older structures, the design itself is unfavourable to seismic safety. In this respect, seismic isolation presents a unique solution, since it enables greater seismic resistance of architectural heritage places with minimal intervention in the structure itself.

The article deals with a special technical aspect of designing base isolated structures with elastomeric isolators, by considering the condition that the elastomeric isolators cannot bear any tensile forces. Allowable height-to-width aspect ratios for different vibration periods, damping, various ground conditions and different design ground accelerations are presented. The horizontal and the vertical accelerations are obtained with the appropriate Eurocode 8 [2] response spectra, as well as with a dynamic analysis of seven near-fault ground motion.

\section{General requirements for base isolation design}

The design of base isolation is a demanding task, as we are dealing with a dynamic system in which the stiffness of the superstructure as well as the stiffness of the base isolation plays an important role. An inadequately designed system can do more damage than good if it moves the structure's vibration period to the prevailing seismic periods, thus causing a resonance response. Seismic isolation is most effective in structures whose fundamental vibration period is in the spectrum's plateau (the constant accelerations branch of the spectrum). In this case, by extending the vibration period we reduce the seismic forces by several times [3-5]. However, we need to be much more careful with structures with very short vibration periods (less than $0.2 \mathrm{~s}$ ), which can, with the use of base isolation, be shifted to an unfavourable resonance range. The general requirements which have to be fulfilled when designing isolators are presented in 
the European regulation on designing earthquake resistant structures - Eurocode 8. The general requirements are described in detail and explained in [5-7].

\section{Special requirements for elastomeric isolators}

The effectiveness of a base isolation system of a slender rigid object on elastomeric isolators depends also on the height-to-width aspect ratio of the superstructure [8-10]. Hino et al. [10] present the design of a slender rigid object on elastomeric isolators based on: (a) ultimate state of tensile strength of isolators, (b) ultimate state of drift of the base isolation story under seismic loading, (c) ultimate state of the axial compressive stress of isolators under dead loads and (d) the prediction of overturning moment at the base under seismic loading.

Elastomeric isolators usually possess very small tensile strength and develop relatively large strains during tensile loading [3, 4, 7]. In this article we present the limit aspect ratios based on point (a), under the condition that the elastomeric isolators cannot bear any tensile forces.

\subsection{Limit aspect ratios based on the rocking and liftoff prevention criteria}

The combined action of uplift forces and end moments may subject the elastomeric isolators to high tensile stresses. This can lead to the disconnection of isolators from the superstructure, which can eventually cause the collapse of the entire structure [8]. Therefore, one of the main criteria for determining the limit aspect ratio of a slender base isolated structure is the prevention of »rocking" and »liftoff" phenomena. The rocking phenomenon occurs when the edge of the superstructure's base lifts up and rocks around its corners, while in the liftoff phenomenon the entire base of the superstructure lifts up due to high uplift forces.

Figure 1 represents a base isolation system in which a superstructure of height $H$ and width $B$ is isolated with $n$ rows of identical elastomeric isolators. It is assumed that the isolators are uniformly distributed throughout the layout in an orthogonal grid. The distance between the rows is constant and equals to $\Delta r$. We have assumed that the superstructure is a rigid body, which moves on the isolation system in the horizontal and/or vertical direction. We believe that the given assumption is reasonable for architectural heritage buildings, which are usually very rigid, but cannot withstand much tensile stress in elastic range. The mass $m$, which accounts for the mass of the superstructure and the mass of the base isolation system, is located in the centre of mass on the height $h_{m}$. We also assume that the superstructure is symmetrical, so that the mass $m$ is always located on $B / 2$ in the centre of the building width. The external forces acting on the system in the centre of mass are the horizontal force $F_{H}$, which represents the horizontal earthquake force, and the total vertical force $F_{V}$, which represents the sum of upward vertical earthquake force on the system and downward total weight of the system. 


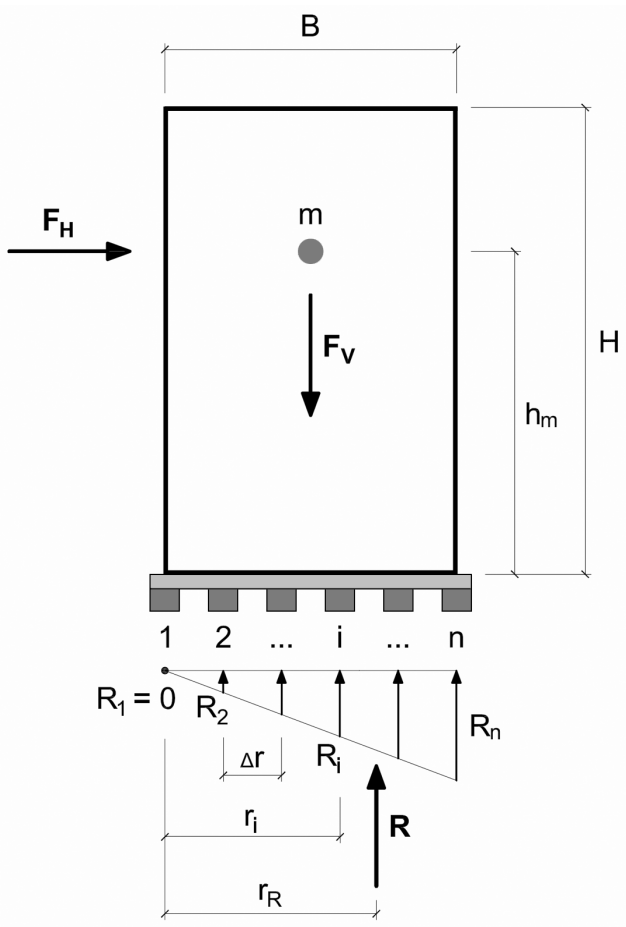

Figure 1: External forces and base reactions of a base isolated rigid body just before entering the rocking phase.

The limit height-to-width $(H / B)$ aspect ratio of the system has been determined from the condition that the elastomeric isolators cannot bear any tensile stresses, i.e. the »rocking prevention « criterion. When the horizontal force $F_{H}$ increases to a certain limit value, tensile stresses appear in one of the edge rows of isolators. As a result the edge of the base of the superstructure lifts up. Figure 1 shows the base isolated system just before it enters the rocking phase; when the base reaction $R_{l}$ in the first row of isolators equals zero and all other reactions $\left(R_{2}\right.$ to $\left.R_{n}\right)$ are producing compressive stresses in the isolators.

The rocking prevention criterion can be written as the moment equilibrium condition on the first row of isolators:

$$
F_{H} \cdot h_{m}+F_{V} \cdot \frac{B}{2}=R \cdot r_{R}
$$

The moment on the first row of isolators caused by the resultant of base reactions $R$ with the lever arm $r_{R}$ can be expressed as a sum of moments of each base reaction $R_{i}$ with its lever arm $r_{i}$ :

$$
R \cdot r_{R}=\sum_{i=1}^{n} R_{i} \cdot r_{i}
$$


Because the distance $\Delta r$ between the rows of isolators is constant, it can be expressed as $\Delta r=B /(n-1)$. Each lever arm can thus be written as:

$$
r_{i}=(i-1) \cdot \frac{B}{n-1}
$$

For constant $\Delta r$ the reaction in the $i$-th row $R_{i}$ can be expressed as a ratio of the maximum base reaction $R_{n}$ :

$$
R_{i}=R_{n} \cdot \frac{r_{i}}{B}
$$

From the vertical equilibrium condition $\sum_{i=1}^{n} R_{i}=F_{V}$ we can express the maximum base reaction $R_{n}$ by considering eqn (4):

$$
R_{n}=\frac{F_{V} \cdot B}{\sum_{i=1}^{n} r_{i}}=\frac{2 F_{V}}{n}
$$

By considering eqn (3), eqn (4) and eqn (5) we can rewrite eqn (2) as:

$$
\sum_{i=1}^{n} R_{i} \cdot r_{i}=\frac{R_{n}}{B} \cdot \sum_{i=1}^{n} r_{i}^{2}=F_{V} \cdot B \cdot \frac{1-2 n}{3-3 n}
$$

If we consider eqn (6) in the initial moment equilibrium condition given in eqn (1) and express the quotient $h_{m} / B$, we get:

$$
\frac{h_{m}}{B}=\frac{1}{2} \cdot \frac{F_{V}}{F_{H}}\left(2 \cdot \frac{1-2 n}{3-3 n}-1\right)
$$

Coefficients $k_{m}$ and $k_{n}$ have been used to represent the effect of the mass height and the effect of the number of isolators, respectively. They are defined as:

$$
\begin{array}{ll}
k_{m}=\frac{h_{m}}{H} & ; \quad k_{m} \in[0,1] \\
k_{n}=3-\frac{6}{n+1} \quad ; \quad & k_{n} \in[1,3] \text { and } n \geq 2
\end{array}
$$

We can see from Figure 2 and eqn (9) that $k_{n}=1$ if the elastomeric isolators are distributed in only two rows $(n=2)$. By increasing the number of rows the discrete support system represented by the elastomeric isolators converges to a uniformly supported layout and thus the value of $k_{n}$ converges towards 3 .

Let us now define $\chi$ as the normalized limit $H / B$ aspect ratio, which can be acquired from eqn (7) by considering coefficients $k_{m}$ and $k_{n}$ :

$$
\chi \equiv k_{m} \cdot k_{n} \cdot \frac{H}{B}=\frac{1}{2} \cdot \frac{F_{V}}{F_{H}}
$$

The limit aspect ratio $\chi$ denotes the normalized limit $H / B$ aspect ratio of a base isolated rigid body in which the combination of horizontal and vertical forces do not cause any tensile stresses in the elastomeric isolators. Eqn (10) 


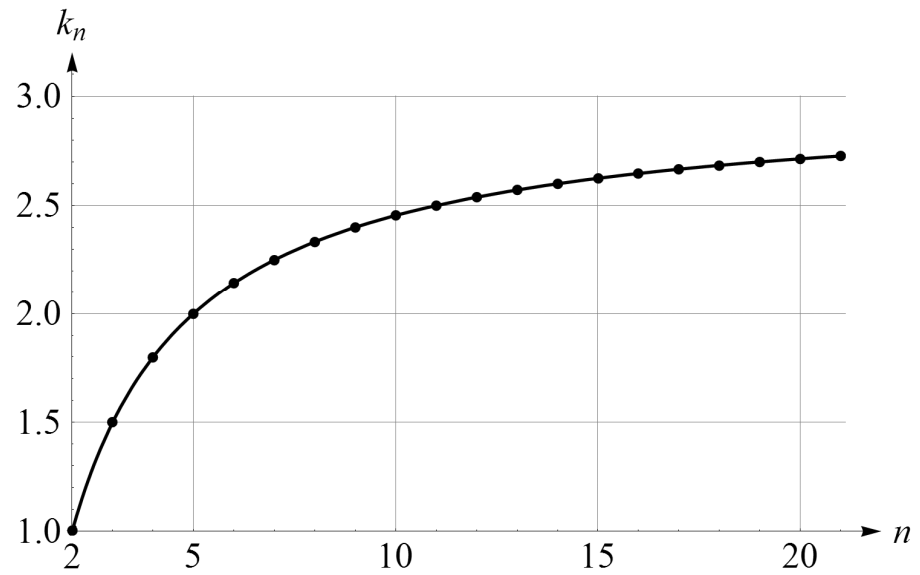

Figure 2: $\quad$ Coefficient $k_{n}$ with respect to the number of rows of isolators $n$.

represents the rocking prevention criterion written with respect to the position of the centre of mass, the number of isolators and the $H / B$ aspect ratio for given combination of vertical and horizontal forces acting on the object. In eqn (10) the actual limit $H / B$ aspect ratio is normalized with coefficients $k_{m}$ and $k_{n}$. If both coefficients equal $1\left(h_{m}=H\right.$ and $\left.n=2\right)$, then the normalized limit aspect ratio $\chi$ represents the actual limit aspect ratio $H / B$.

The second criterion for determining the limit aspect ratio of a base isolated structure is the prevention of the liftoff phenomenon, which occurs when the vertical force $F_{V}$ causes an uplift of the base of the superstructure. This criterion thus implies that the total vertical force $F_{V}$, which accounts for the vertical earthquake force and the total weight of the system, must always be equal or greater than zero, so that the weight of the structure is greater than the vertical earthquake force.

\subsection{Calculation of the limit aspect ratio based on the acceleration response spectra}

In this chapter the normalized limit $H / B$ aspect ratio $\chi$ has been determined by considering the elastic acceleration response spectra from the European building code Eurocode 8 . In a linear response spectrum analysis the forces $F_{H}$ and $F_{V}$ equal:

$$
\begin{aligned}
& F_{H}=m \cdot S_{a, H}(T) \\
& F_{V}=m \cdot g-m \cdot S_{a, V}\left(T_{V}\right)
\end{aligned}
$$

The accelerations $S_{a, H}(T)$ and $S_{a, V}\left(T_{V}\right)$ represent the horizontal and vertical spectral acceleration for the corresponding horizontal and vertical vibration period ( $T_{H} \equiv T$ and $T_{V}$ ). The symbol $g$ represents the acceleration of gravity. We have assumed that the vertical vibration period is always in the plateau of the 
vertical response spectrum, in order to obtain a conservative estimation of the vertical force acting on the system. The Eurocode 8 also demands that the horizontal and vertical ground components should be considered for two combinations:

Combination 1: $\quad 1.0 \cdot S_{a, H}$ and $0.3 \cdot S_{a, V}$

Combination 2: $\quad 0.3 \cdot S_{a, H}$ and $1.0 \cdot S_{a, V}$

We can now write eqn (10) by considering both combinations from eqn (12a, b) together with the definition of the elastic response spectra [2] and eqn $(11 \mathrm{a}, \mathrm{b})$ :

$$
\begin{aligned}
& \text { Combination 1: } \quad \chi_{1}=\frac{1-0.81 \cdot a_{g} \cdot \eta}{5 \cdot S \cdot T_{c} \cdot a_{g} \cdot \eta \cdot f(T)} \\
& \text { Combination 2: } \quad \chi_{2}=\frac{1-2.7 \cdot a_{g} \cdot \eta}{1.5 \cdot S \cdot T_{c} \cdot a_{g} \cdot \eta \cdot f(T)}
\end{aligned}
$$

The symbol $a_{g}$ denotes the design ground acceleration, expressed in the units of $g, \eta=\sqrt{10 /(5+\xi)} \geq 0.55$ represents the damping correction factor, which is a function of the viscous damping ratio of the isolation system $\xi$ (expressed in percent), $S$ is the soil parameter, and the period $T_{c}$ represents the limit of the constant spectral acceleration range. The function $f(T)$ defines the shape of the elastic acceleration response spectrum in accordance with Eurocode 8 and can be expressed in terms of the vibration period $T$ as:

$$
\begin{array}{ll}
f(T)=1 / T & ; \quad \text { if } T_{c} \leq T \leq T_{d} \\
f(T)=T_{d} / T^{2} & ; \quad \text { if } T \geq T_{d}
\end{array}
$$

The vibration period $T_{d}$ represents the beginning of the constant displacement response range of the spectrum.

In order to prevent the liftoff phenomenon the vertical force $F_{V}$ must always be positive. This means that the numerators in eqn $(13 a, b)$ must always be greater than zero. By considering this condition we can express the maximum allowable design ground acceleration $a_{g, \max }$ as:

$$
a_{g, \max }=\frac{1}{2.7 \cdot \eta}
$$

For example, for a typical base isolated system with the viscous damping ratio of $\xi=10 \%$, the maximum allowable design ground acceleration equals $a_{g, \max }=$ $0.454 \mathrm{~g}$.

By considering eqn $(13 \mathrm{a}, \mathrm{b})$ we can now determine the limit aspect ratio $\chi=\min \left(\chi_{1}, \chi_{2}\right)$ as the lower value of combinations 1 and 2 . The limit aspect ratio is determined with respect to the horizontal vibration period $T$ for a $10 \%$ 

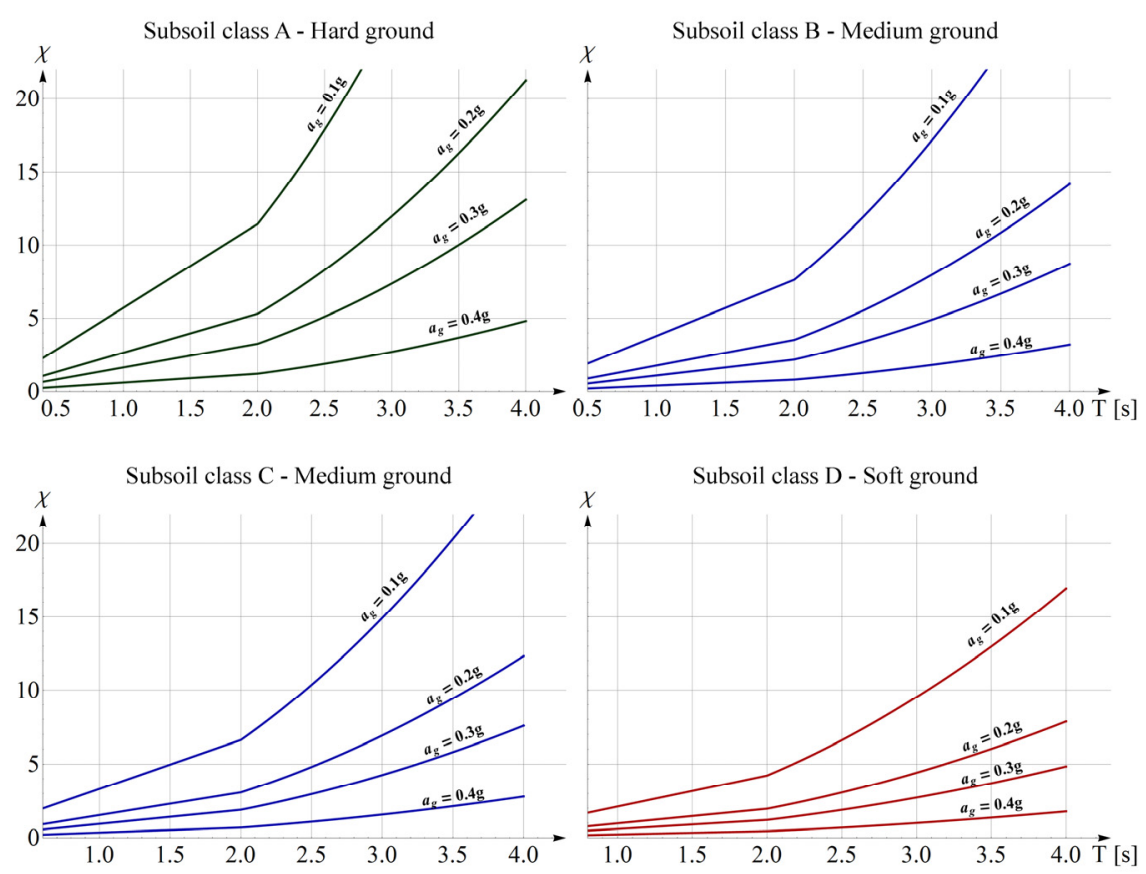

Figure 3: $\quad$ Limit aspect ratio $\chi$ with respect to the horizontal vibration period for different ground conditions.

viscous damping ratio, different ground conditions and various design ground accelerations.

Figure 3 presents the limit aspect ratio $\chi$ for four different ground conditions, which correspond to subsoil classes A, B, C and D from Eurocode 8. Class A represents hard ground conditions, classes $\mathrm{B}$ and $\mathrm{C}$ represent medium ground conditions, while class D represents soft ground conditions. The curves are plotted for four design ground accelerations in the range of $a_{g}=0.1 \mathrm{~g}$ to $a_{g}=$ $0.4 \mathrm{~g}$. The range of the horizontal vibration periods $T$ for the plotted curves varies, depending on the ground conditions. For each ground class the starting period corresponds to the limit of the plateau of the horizontal response spectrum $\left(T_{c}\right)$. They equal $T_{c}=0.4 \mathrm{~s}$ for class $\mathrm{A}, T_{c}=0.5 \mathrm{~s}$ for class $\mathrm{B}, T_{c}=0.6 \mathrm{~s}$ for class $\mathrm{C}$ and $T_{c}=0.8 \mathrm{~s}$ for class $\mathrm{D}$. The end period always equals $T=4 \mathrm{~s}$. Periods greater than $4 \mathrm{~s}$ produce large displacements of the isolation system and are thus not appropriate for practical use.

\subsection{Calculation of the limit aspect ratio based on dynamic analysis}

The forces $F_{H}$ and $F_{V}$ in a dynamic time-history analysis can be expressed with the respect to the horizontal response acceleration $a_{H}(t)$ and the vertical response acceleration $a_{\nu}(t)$ acting on the centre of mass of the system: 


$$
\begin{aligned}
& F_{H}=m \cdot a_{H}(t) \\
& F_{V}=m \cdot g-m \cdot a_{V}(t)
\end{aligned}
$$

These response accelerations are functions of the ground accelerations, damping of the system and the vibration periods of the system and can be calculated by means of various time-history calculation methods [11]. It is important to note, that the maximum values of $a_{H}(t)$ and $a_{V}(t)$ usually do not occur at the same time $t$. Furthermore, the critical combination that determines the limit aspect ratio $\chi$ does not necessarily occur when one of these accelerations obtains its maximum value. For the rocking prevention criterion only the combination which at a certain time $t$ causes the most unfavourable (minimum) limit aspect ratio $\chi$ is relevant. If we now denote with $a_{H, \text { crit }}$ and $a_{V, \text { crit }}$ the critical combination of the horizontal and vertical response accelerations, which yields the minimum limit aspect ratio $\chi$, we can write eqn (10) as:

$$
\chi=\frac{1}{2} \cdot \frac{1-a_{V, \text { crit }}}{a_{H, \text { crit }}}
$$

The critical response accelerations are expressed in the units of $g$. The horizontal component $a_{H, c r i t}$ depends on the horizontal ground acceleration $a_{g, H}(t)$, damping in the horizontal direction and the horizontal vibration period $T$, while the vertical component $a_{V, c r i t}$ depends on the vertical ground acceleration $a_{g, V}(t)$, damping in the vertical direction and the horizontal vibration period $T_{V}$.

As an example we have determined the limit aspect ratios $\chi$ for a series of seven near-fault ground motions (Table 1), which have fault distances smaller than 15 kilometres [12]. Near-fault motions have been chosen because they produce a long-period pulse in the acceleration history, which does not exist in ground motions recorded at locations further away from the near-fault region [13]. It is expected that such pulsations will produce more critical limit aspect ratios.

All selected records have been recorded on subsoil class B. In Table 1 the peak horizontal ground component $a_{g, H}$, the peak vertical ground component $a_{g, V}$

Table 1: Selected near-fault earthquake acceleration records.

\begin{tabular}{|c|c|c|c|c|c|c|c|}
\hline $\begin{array}{c}\text { Record } \\
\text { number }\end{array}$ & Earthquake Name & $\begin{array}{c}\text { NGA seq. } \\
\text { number }\end{array}$ & Year & $\begin{array}{c}\text { Fault } \\
\text { distance } \\
(\mathrm{km})\end{array}$ & $\begin{array}{c}\mathrm{a}_{\mathrm{g}, \mathrm{H}} \\
(\mathrm{g})\end{array}$ & $\begin{array}{c}\mathrm{a}_{\mathrm{g}, \mathrm{V}} \\
(\mathrm{g})\end{array}$ & $\mathrm{a}_{\mathrm{g}, \mathrm{V}} / \mathrm{a}_{\mathrm{g}, \mathrm{H}}$ \\
\hline I & Friuli, Italy & 0130 & 1976 & 11.03 & 0.109 & 0.074 & 0.68 \\
\hline II & Santa Barbara, USA & 0136 & 1978 & 12.16 & 0.203 & 0.077 & 0.38 \\
\hline III & Dinar, Turkey & 1141 & 1995 & 3.36 & 0.352 & 0.137 & 0.39 \\
\hline IV & Loma Prieta, USA & 0779 & 1989 & 3.88 & 0.966 & 0.886 & 0.92 \\
\hline V & Duzce, Turkey & 1612 & 1999 & 4.17 & 0.147 & 0.106 & 0.72 \\
\hline VI & Landers, USA & 0879 & 1992 & 2.19 & 0.789 & 0.818 & 1.04 \\
\hline VII & Kocaeli, Turkey & 1171 & 1999 & 3.12 & 0.376 & 0.259 & 0.69 \\
\hline
\end{tabular}

${ }^{*}$ See the NGA database [15] 
and the ratio $a_{g, V} / a_{g, H}$ are presented for each record. This ratio can be used to study the influence of the vertical component on the overall seismic response behaviour of structures. For normal earthquakes, it is expected to be around $2 / 3$ [14]. The average $a_{g, V} / a_{g, H}$ ratio for the selected records equals 0.69 . In the analysis the peak horizontal ground component has been scaled to $a_{g, H}=0.2 \mathrm{~g}$. The same scale factor has been used to scale the peak vertical ground component $a_{g, V}$, so that the $a_{g, V} / a_{g, H}$ ratio remains unchanged. The viscous damping ratio in both horizontal and vertical direction has been taken as $10 \%$ and the vertical vibration period has been taken as $T_{V}=0.1 \mathrm{~s}$.

The $\chi$ ratios have been calculated numerically by solving the Duhamel's integral for the given horizontal and vertical ground records, for all vibration periods $T$ in the range of interest. For this purpose a computer program has been written in the Mathematica programming language [16].

Figure 4 presents the limit aspect ratio $\chi$ for the selected ground records, together with their mean curve and the curve obtained by the response spectrum analysis based on Eurocode 8 (see chapter 3.2). We can see that the mean curve gives higher limit aspect ratio values as the response spectrum curve (EC8 curve) for all vibration periods $T$. If we however, consider the $\chi$ curves for each ground record separately, we can see that some ground records, especially III, IV and VII give unconservative limit aspect ratios with the respect of those obtained by Eurocode 8. This means that for each of these records the base isolated system designed in accordance with the EC8 curve would develop tension stresses in the isolation system, which could eventually lead to a malfunction of the elastomeric isolators and ultimately to the overturning of the structure.

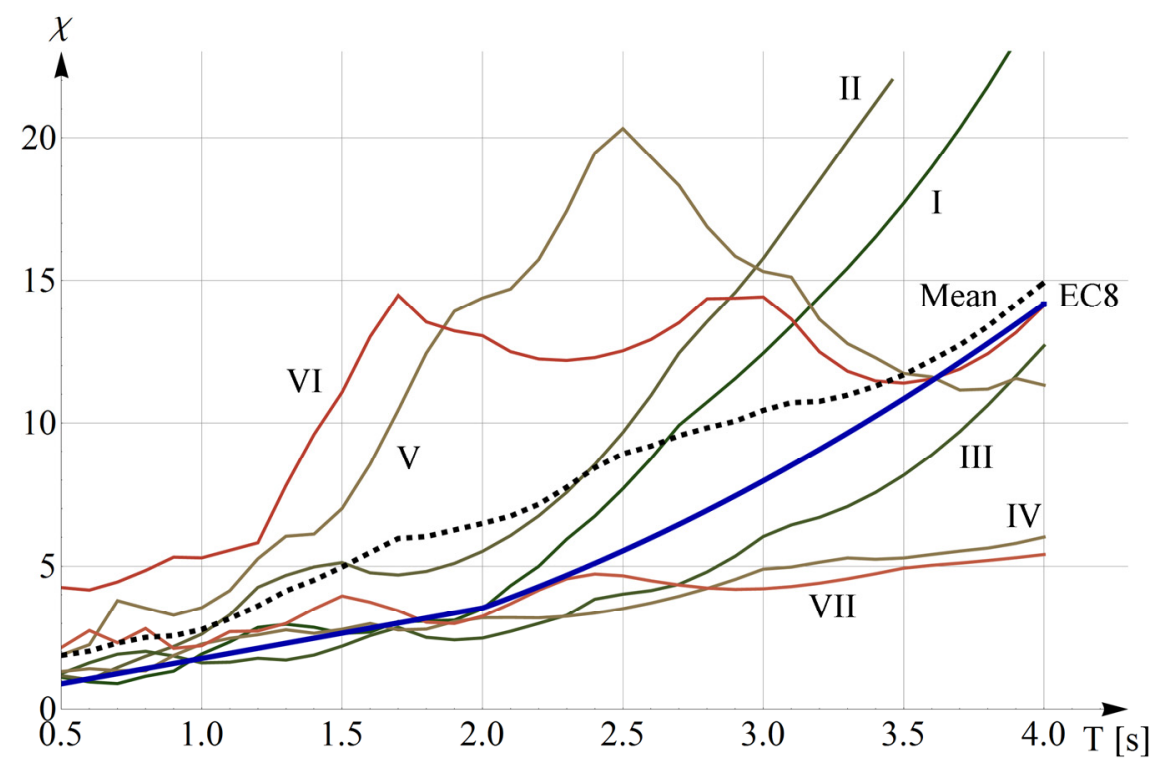

Figure 4: Comparison of the limit aspect ratio $\chi$ based on dynamic and response spectrum analysis. 


\section{Conclusion}

Since inappropriate restoration of heritage architecture can do irreversible damage to the structure, such actions should be carefully planned. It is especially desirable that the retrofit influence on the object's architecture is minimized. This can be achieved with seismic isolation, which generally does not interfere much with the aesthetics and functionality of an existing object.

The article considers the maximum height-to-width aspect ratios of rigid base isolated objects of heritage architecture on the condition, that the elastomeric isolators cannot bear any tensile forces. Slender base isolated structures with high height-to-width aspect ratios are prone to develop the rocking or liftoff phenomena and should be designed according to the limit aspect ratio presented herein. The limit aspect ratio $\chi$ presented in the article represents the normalized limit $H / B$ aspect ratio of a base isolated rigid body in which the combination of horizontal and vertical forces do not cause any tensile stresses in the elastomeric isolators. The aspect ratio has been normalized with coefficients $k_{m}$ and $k_{n}$, which represent the effect of the position of the centre of mass and the effect of the number of isolators, respectively.

By comparing the limit aspect ratios obtained from the response spectrum analysis with those obtained with the dynamic analyses, we can conclude that the results from the response spectrum analysis are generally conservative if compared with average results for a series of different ground motions. However, if we observe each acceleration record separately, some examined near fault records have produced smaller limit aspect ratios due to more critical combinations of horizontal and vertical response accelerations.

It generally holds true that the rocking and liftoff prevention criteria are predominant in designing base isolation of tall, slender objects. For objects with lower height-to-width aspect ratios other general criteria, which are briefly mentioned in chapter 2 , govern the design of a base isolation system.

\section{References}

[1] The Burra Charter. ICOMOS. http://www.icomos.org/australia/burra.html

[2] CEN, Eurocode 8: Design of structures for earthquake resistance - Part 1: General rules, seismic actions and rules for buildings, EN 1998-1. European Committee for Standardization: Brussels, 2004.

[3] Naeim, F., Kelly, J. M., Design of seismic isolated structures: from theory to practice. John Wiley \& Sons, Inc.: New York, 1999.

[4] Skinner, R. I., Robinson, W. H., McVerry, G. H., An introduction to seismic isolation. John Wiley \& Sons Ltd.: West Sussex, 1993.

[5] Christopoulos, C., Filiatrault, A., Principles of Passive Supplemental Damping and Seismic Isolation. IUSS Press: Pavia, 2006.

[6] Komodromos, P., Seismic Isolation for Earthquake Resistant Structures. WIT Press: London, 2000.

[7] Kelly, J. M., Earthquake-Resistant Design with Rubber. Cambridge University Press: Cambridge, 1997. 
[8] Li, H., Wu, X. X., Limitations of the height-to-width ratio for base isolated buildings under earthquake. The structural design of tall and special buildings, 15, pp. 277-287, 2006.

[9] Contento, A., Di Egidio, A., Investigations into the benefits of base isolation for non-symmetric rigid blocks. Earthquake Engineering and Structural Dynamics, 38(7), pp. 849 - 866, 2008.

[10] Hino, J., Yoshitomi, S., Tsuji, M., Takewaki, I., Bound of aspect ratio of base isolated buildings considering nonlinear tensile behaviour of elastomeric isolators. Structural Engineering and Mechanics, 30(3), pp. $351-368,2008$.

[11] Chen, W. F., Scawthorn, C., Earthquake Engineering Handbook. CRC Press: New York, 2003.

[12] Hernández, J. J., López, O. A., Evaluation of combination rules for peak response calculation in three-component seismic analysis. Earthquake Engineering and Structural Dynamics, 32(10), pp. 1585-1602, 2003.

[13] Chopra, A. K., Chintanapakdee, C., Comparing response of SDF systems to near-fault and far-fault earthquake motions in the context of spectral regions. Earthquake Engineering and Structural Dynamics, 30(12), pp.1769-1789, 2001

[14] Salazar, A. R., Haldar, A., Structural responses considering the vertical component of earthquakes. Computers and Structures, 74, pp. 131-145, 2000.

[15] NGA Database, peer.berkeley.edu/nga/

[16] Wolfram Mathematica, www.wolfram.com 